\title{
DINAMIKA DAN KEBIJAKAN PENGEMBANGAN EKONOMI KELAUTAN INDONESIA
}

\section{Dynamics and Policies of Indonesia's Ocean Economic Development}

\author{
*Kastana Sapanli, Tridoyo Kusumastanto, Sugeng Budiharsono, dan Agus Sadelie \\ IPB University \\ JI. Raya Dramaga Kampus, IPB Dramaga Bogor, 16680 Jawa Barat, Indonesia \\ Diterima tanggal: 22 Januari 2020; Diterima setelah perbaikan: 24 April 2020;
}

Disetujui terbit: 25 Juni 2020

\begin{abstract}
ABSTRAK
Amanat UU 32 tahun 2014 tentang Kelautan salah satunya percepatan dan penguatan ekonomi nasional dari potensi kelautan yang ada. Penelitian ini mengkaji kontribusi PDB ekonomi kelautan; dampak pengembangan ekonomi kelautan; dan implikasi kebijakan pengembangan ekonomi kelautan. Metode penelitian menggunakan analisis data sekunder. Data yang digunakan adalah data sekunder tahun 2010-2015 yang diperoleh dari Badan Pusat Statistik (BPS). Data dianalisis secara deskriptif kuantitatif menggunakan model I-O (Input-Output) yang diupdate ke tahun 2015. Hasil penelitian menunjukkan bahwa persentase produk kelautan terhadap PDB terus meningkat mencapai $28.01 \%$ pada tahun 2015. Berdasarkan kajian terhadap dampak ekonomi yang dihasilkan, perlu diprioritaskan pengembangan ekonomi kelautan pada tiga sektor yaitu: industri kelautan, perikanan dan pariwisata bahari. Prinsip kebijakan pengembangan ekonomi kelautan harus inovatif dan berkelanjutan yang bertumpu pada peningkatan daya saing, modernisasi sistem produksi, penguatan kapasitas pelaku industri dan berbasis komoditas.
\end{abstract}

Kata Kunci: dampak ekonomi; ekonomi kelautan; kebijakan kelautan; kontribusi PDB; pembangunan

\begin{abstract}
Law number 32 of 2014 about The Sea mandates the national economic acceleration and empowerment from the potential of marine. This research examined the contribution of the ocean economy to GDP, impact of ocean economic development, and policy implication of ocean economic development. The research used secondary data analysis method. It used secondary data of 2010-2015 that were collected from Statistics Indonesia. Data were analyzed with quantitative descriptive method with I-O model (input-output), that were updated to 2015. The results showed that the percentage of marine products contribution to GDP increased to $28.01 \%$ in 2015 . Based on the analysis of economic impact, it is necessary to prioritize the ocean economic development on three sectors: marine industry, fisheries, and marine tourism. The ocean economic development policies must be innovative, sustainable, increasing competitiveness, modernizing production systems, and strengthening the capacity of industrial and commodity-based players.
\end{abstract}

Keywords: economic impact; ocean economic; ocean policy; GDP contribution; development

\section{PENDAHULUAN}

Pencapaian visi dan misi pembangunan nasional di bidang kelautan merupakan amanat undang-undang yang wajib dipenuhi. Targettarget pembangunan kelautan sebagaimana telah digariskan dalam UU No. 17 Tahun 2007 tentang Rencana Pembangunan Jangka Panjang 2005-2025 merupakan milestone yang harus dicapai secara gradual dalam masa sepuluh tahun (2015-2025). Kebijakan yang dikeluarkan oleh pemerintah hendaknya selalu berorientasi kepada pembangunan kelautan yang berkelanjutan. Sebagai sebuah wilayah yang berbasis kepulauan, maka menurut Kusumastanto (2006) bidang kelautan terdiri dari sektor perikanan, pariwisata bahari, pertambangan laut, industri kelautan, perhubungan laut, bangunan kelautan, dan jasa kelautan, dapat dijadikan arus utama (mainstream) dalam kebijakan pembangunannya. Mempertimbangkan potensi sektor kelautan yang luas, dan perlu upaya pencapaian yang sistemik, pemerintah menyiapkan kerangka pencapaian melalui UU No. 32 tahun 2014 tentang Kelautan.

Ekonomi kelautan dapat menjadi penyokong utama perekonomian sebuah wilayah (Colgan, 2016). Ada beberapa alasan penting untuk 
diperhatikan yaitu pertama, kapasitas suplai sangat besar, sementara permintaan terus meningkat. Kedua, pada umumnya output dapat diekspor, sedangkan input berasal dari sumber daya lokal. Ketiga, dapat membangkitkan industri hulu dan hilir yang besar, sehingga menyerap banyak tenaga kerja. dan terakhir pada umumnya berlangsung di daerah. Berdasarkan hal tersebut maka salah satu penyokong ekonomi kelautan adalah industri transportasi laut (Jiang et al., 2014). Sektor inilah yang menjadi kunci dalam interaksi dan pengembangan bisnis ekonomi kelautan. Oleh karena itu, sangat penting memastikan dukungan infrastrukur transportasi laut seperti pelabuhan dan jasa kepelabuhan agar perdagangan antar wilayah dapat berjalan lancar (Viederyte, 2014).

Tahun 2017, Pendapatan Domestik Bruto (PDB) Perikanan berhasil tumbuh 5,95 persen setelah sempat terpuruk di tahun 2016. Meskipun demikian, capaian ini masih lebih rendah dibandingkan target yang ditetapkan pemerintah sebesar 8 persen (BPS, 2018). Pertumbuhan PDB Perikanan tahun 2018 ditargetkan lebih tinggi lagi sebesar 11 persen (KKP, 2018). Dengan capaian tahun 2017 dimana PDB Perikanan tumbuh di bawah 10 persen, maka menjadi sebuah pekerjaan rumah dengan tantangan yang besar guna mewujudkan target ini.

Secara agregat, kelautan memberikan kontribusiyang tergolong besar dalam perekonomian nasional (Kusumastanto, 2003; Dahuri, 2003; Fauzi, 2005). Dalam ukuran nilai PDB atas dasar harga berlaku sejak tahun 1995 hingga tahun 2005, kontribusi sektor kelautan dalam perekonomian Indonesia, tergolong besar dan memperlihatkan peningkatan yang nyata. Pada tahun 1995, PDB sektor kelautan diketahui sekitar $12,38 \%$ dari PDB nasional, dan pada tahun 2000 meningkat menjadi sekitar $20.05 \%$ dari PDB nasional (Kusumastanto, 1998; 2003). Peningkatan PDB kembali terjadi tahun 2005 menjadi sekitar $22,23 \%$ (Tajerin, 2013). Total potensi sektor kelautan Indonesia mencapai US\$1.2 triliun per tahun atau 7 kali lipat Anggaran Pendapatan Belanja (APBN)

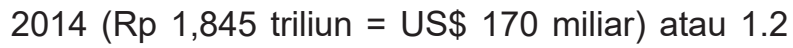
kali PDB nasional saat ini, namun sektor ekonomi kelautan belum seluruhnya diatur landasan pengelolaannya dan konsep pengelolaannya dengan baik (Kusumastanto, 2015).

Beberapa negara di dunia telah membuat program kebijakan kelautan terpadu yang mampu mendeskripsikan gambaran potensi kelautan baik kekuatan dan kelemahan yang diperkuat dengan landasan hukum yang terintegrasi antar sektor kelautannya (Markus et al., 2011; OECD, 2016). Di dalam merancang sebuah kebijakan, penting melakukan identifikasi hubungan keterkaitan antar sektor baik secara ekonomi maupun hubungannya terhadap lingkungan laut. Hal ini menjamin terlaksananya kebijakan secara efektif (Bainbridge et al., 2011). Sievanen et al. (2011) mengemukakan bahwa keberhasilan kebijakan nasional ditentukan oleh keterkaitan isu-isu yang berlaku di tingkat lokal serta sistem laut yang terdiri dari isu-isu ekonomi, sosial, politik, dan kelembagaan serta lingkungan. Namun, masalah ego sektoral yang menimbulkan konflik pemanfaatan, tumpang tindih yurisdiksi dan masalah lingkungan menjadi kendala dalam pelaksanaannya (Saharuddin, 2001 dan Dankel et al., 2012). Kondisi perekonomian global yang lesu pada masa pandemi covid 19 ini berdampak pada gangguan bisnis dan industri, termasuk pada sektor-sektor kelautan. Babaa et al. (2014) menyatakan bahwa gangguan ekonomi menyebabkan terjadinya peningkatan pengangguran akibat lesunya perekonomian baik dari skala regional, nasional hingga global. Hal ini mengakibatkan bahwa potensi yang ada juga tidak tergali dan sehingga tidak dapat dimanfaatkan sebagai aset strategis dalam percaturan geoekonomi dan geopolitik dunia.

Dalam mengoptimalkan pemanfaatan potensi kelautan yang ada dan untuk pengembangan Indonesia sebagai negara maritim, maka dalam makalah ini disajikan kajian komprehensif terhadap struktur ekonomi dan keterkaitan antar sektor yang menjadi pendukung ekonomi bidang kelautan. Berdasarkan hasil tersebut akan mampu menjadi pertimbangan para pengambil kebijakan khususnya pemerintah dan pihak swasta sebagai investor untuk mengembangkan bisnis kelautan yang tidak hanya berorientasi profit, namun juga berdampak luas pada perekonomian nasional.

Metode penelitian yang digunakan dalam studi ini adalah analisis data sekunder dengan analisis deskriptif kuantitatif. Data yang dipergunakan dalam penelitian ini diperoleh dari data sekunder. Pengumpulan data sekunder terkait ekonomi kelautan yang tersebar di berbagai instansi pemerintah. Basis data yang digunakan adalah data yang disajikan oleh Badan Pusat Statistik berupa Tabel Input-Output (I-O) tahun 2010 yang diupdate ke tahun 2015 dengan metode 
non survei RAS yaitu memperkirakan matriks koefisien input yang baru $(\mathrm{A}(\mathrm{t}))$ berdasarkan informasi koefisien input tahun dasar $(A(0))$. Dalam rangka melakukan pemetaan potensi dan keragaan ekonomi kelautan, dilakukan agregasi sektor-sektor sehingga diperoleh data yang lebih rinci terutama berdasarkan sektor-sektor dalam perekonomian (Bui, 2012; 2013).

Menurut Park \& Kildow (2014) dan Kildow \& Colgan (2005) ekonomi laut terkait dengan kegiatan ekonomi sebagai aspek industri, langsung atau tidak langsung terkait dengan laut (termasuk pantai) sebagai aspek geografis. Tabel I-O ini digunakan untuk melihat peranan bidang kelautan yaitu sektor perikanan, pariwisata bahari, pertambangan laut, industri kelautan, angkutan laut, bangunan kelautan, jasa kelautan dalam pembentukan permintaan dan penawaran, output, nilai tambah bruto dan permintaan akhir yang dianalisis secara deskriptif dan dampaknya. Analisis deskriptif menggambarkan kontribusi ekonomi terdiri dari analisis struktur permintaan dan penawaran, analisis struktur output, analisis struktur nilai tambah bruto dan analisis struktur permintaan akhir. Analisis dampak untuk melihat sektor yang paling memberikan multiplier effect terhadap ekonomi menggunakan analisis dampak output, analisis dampak kesempatan kerja, analisis dampak pendapatan, daya penyebaran dan derajat kepekaan (BPS, 2000).

Pendekatan model ini dikembangkan melalui analisis dinamik yang dikembangkan Moffat \& Hanley (2001) dengan komponen-komponen pada Tabel I-O tahun 2010 yang di update ke tahun 2015. Konsep dasar pada tabel ini terbagi atas 4 kuadran yang disajikan pada Gambar 1.

\begin{tabular}{|c|c|}
\hline $\begin{array}{c}\text { Kuadran I: } \\
\text { Transaksi antar kegiatan (nxn)/ } \\
\text { Quadrant I: } \\
\text { Transactions between activities (nxn) }\end{array}$ & $\begin{array}{c}\text { Kuadran II: } \\
\text { Permintaan akhir }(\mathrm{nxm}) / \\
\text { Quadrant II: } \\
\text { Final request }(\text { nxm) }\end{array}$ \\
\hline $\begin{array}{l}\text { Kuadran III: } \\
\text { Input primer sektor industri (pxn)/ } \\
\text { Quadrant III: } \\
\text { Industrial sector primary input (pxn) }\end{array}$ & $\begin{array}{c}\text { Kuadran IV: } \\
\text { Distribusi input primer } \\
\text { ke-permintaan akhir (pxm)/ } \\
\text { Quadrant IV: } \\
\text { Primary input distribution } \\
\text { to-final request (pxn) }\end{array}$ \\
\hline
\end{tabular}

Gambar 1. Kerangka Dasar Model Input-Output. Figure 1. Basic Framework for Input-Output Model.

Kuadran I (Intermediate Quadran) merupakan transaksi antara, yaitu transaksi barang dan jasa yang digunakan dalam proses produksi.
Kuadran ini memberikan informasi mengenai saling ketergantungan antar sektor produksi dalam suatu perekonomian (Leontief, 1970). Dalam analisis Input-Output, kuadran ini memiliki peranan yang sangat penting karena kuadran inilah yang menunjukkan keterkaitan antar sektor ekonomi dalam melakukan proses produksinya. Pada kuadran I tergambarkan nilai transaksi antara pada masing-masing sektor ekonomi kelautan dan juga menghasilkan koefisien input (A). Koefisian input akan menjadi parameter utama dalam menentukan penilaian dampak ekonomi dalam perhitungan dampak keterkaitan kedepan dan keterkaitan kebelakang bidang kelautan. Kuadran II (Final Demand Quadran) menunjukkan penjualan barang dan jasa yang dihasilkan oleh sektor-sektor perekonomian untuk memenuhi permintaan akhir. Permintaan akhir adalah output suatu sektor yang langsung dipergunakan oleh rumah tangga $(\mathrm{C})$, pemerintah $(\mathrm{G})$, pembelian modal tetap (I), perubahan stok dan ekspor (NX). Kuadran II menjadi komplementer kuadran I dalam menghitung nilai output kelautan. Kuadran III (Primary Input Quadran) merupakan pembelian input yang dihasilkan diluar sistem produksi oleh sektor-sektor dalam kuadran antara. Kuadran ini terdiri dari pendapatan rumah tangga (upah/ gaji), pajak tak langsung, surplus usaha dan penyusutan. Jumlah keseluruhan nilai tambah ini akan menghasilkan output berupa PDB kelautan yang dihasilkan wilayah tersebut. Kuadran IV (Primary Input-Final Demand Quadran) merupakan kuadran input primer permintaan akhir yang menunjukkan transaksi langsung antara kuadran input primer dengan permintaan akhir tanpa melalui sistem produksi atau kuadran antara. Pada kajian ini kuadran IV tidak dibahas disebabkan keterbatasan informasi pada Tabel I-O.

\section{DINAMIKA KONTRIBUSI EKONOMI KELAUTAN}

Dalam melakukan analisis Input-Output untuk menentukan sektor-sektor di bidang kelautan, maka ada beberapa langkah yang dapat dilaksanakan (Zhao et al., 2014). Langkah pertama adalah mengidentifikasi dari klasifikasi 185 sektor tersebut berdasarkan Klasifikasi Baku Lapangan Usaha Indonesia (KBLI), sektor mana yang terkait dengan kegiatan kelautan. Dari sektor-sektor tersebut, sebagian memang 100 persen aktivitasnya dikategorikan kegiatannya kelautan dan perikanan seperti perikanan laut, pengolahan ikan dan lain-lain. Namun beberapa 
sektor tidak seluruhnya merupakan kegiatan kelautan dan perikanan seperti pariwisata bahari, pertambangan, industri kelautan dan jasa kelautan (Colgan, 2013). Pada makalah ini, sektorsektor kelautan dihitung dengan melakukan perhitungan pada 26 sub sektor pada Tabel I-O dan mengagregasikan ke dalam 7 sektor kegiatankelautan (Kusumastanto, 2006). Pada Tabel 1 berikut disajikan agregasi klasifikasi ekonomi kelautan berdasarkan Tabel I-O tahun 2010.
Dari 26 Sub sektor yang digabung menjadi 7 sektor yang dianalisis, diperoleh hasil berupa nilai persentase produk kelautan terhadap PDB seperti disajikan pada Tabel 2. Berdasarkan Tabel I-O tahun 2005 share PDB kelautan sebesar $25.39 \%$ dari total PDB nasional. Tabel I-O 2010 menunjukkan peningkatan sebesar $27.28 \%$ dan dengan data yang diperoleh pada tahun 2015 menunjukkan kontribusi bidang kelautan telah mencapai 28.01 \%. Kontribusi PDB kelautan tahun 2005, 2010 dan 2015 disajikan pada Tabel 2.

Tabel 1. Agregasi Klasifikasi Sektor Ekonomi Kelautan Berdasarkan Tabel I-O. Table 1. Aggregation of Ocean Economic Sector Classification Based on I-O Table.

\begin{tabular}{|c|c|c|}
\hline $\begin{array}{l}\text { Kode KBLI / } \\
\text { KBLI Code }\end{array}$ & Sub Sektor/Sub Sector & Sektor/Sector \\
\hline 033 & Ikan/Fish & Perikanan/Fisheries \\
\hline 034 & $\begin{array}{l}\text { Udang dan crustacea lainnya/Shrimp and other } \\
\text { crustacea }\end{array}$ & \\
\hline 035 & Biota air lainnya/Other aquatic biota & \\
\hline 036 & Rumput laut dan sejenisnya/Seaweed and its kind & \\
\hline 055 & Ikan Kering dan Ikan Asin/Dried fish and salted fish & \\
\hline 056 & $\begin{array}{l}\text { Hasil Pengolahan dan Pengawetan Ikan/Fish } \\
\text { processing and preservation product }\end{array}$ & \\
\hline 164 & Penyediaan Akomodasi/Accommodation services & Pariwisata Bahari/Marine tourism \\
\hline 165 & $\begin{array}{l}\text { Penyediaan Makan dan Minum/Food and beverage } \\
\text { services }\end{array}$ & \\
\hline 183 & $\begin{array}{l}\text { Jasa Kesenian, Hiburan dan Rekreasi/Arts, } \\
\text { Entertainment and Recreation Services }\end{array}$ & \\
\hline 185 & Jasa Pariwisata Lainnya/Tourism services & \\
\hline 038 & Minyak Bumi/Crude oil & Pertambangan Laut/Ocean Mining \\
\hline 041 & Bijih Timah/Tin ore & \\
\hline 048 & Barang Galian Segala Jenis/Other similar excavation & \\
\hline 049 & $\begin{array}{l}\text { Barang Tambang Mineral Bukan Logam/Non-Metallic } \\
\text { Mineral Mining Goods }\end{array}$ & \\
\hline 050 & Garam Kasar/Coarse salt & Industri Kelautan/Marine Industry \\
\hline 051 & $\begin{array}{l}\text { Jasa pertambangan minyak bumi dan gas alam/ } \\
\text { Petroleum \& natural gas mining services }\end{array}$ & \\
\hline 052 & $\begin{array}{l}\text { Jasa pertambangan dan penggalian lainnya/Other } \\
\text { mining and excavation services }\end{array}$ & \\
\hline 095 & $\begin{array}{l}\text { Barang-barang Hasil Kilang Minyak dan Gas Bumi/ } \\
\text { Oil and Gas Refinery Products }\end{array}$ & \\
\hline 132 & $\begin{array}{l}\text { Kapal dan Jasa Perbaikannya/Ships and Repair } \\
\text { Services }\end{array}$ & \\
\hline 146 & $\begin{array}{l}\text { Hasil gas alam dan buatan/Natural and artificial gas } \\
\text { products }\end{array}$ & \\
\hline 159 & Jasa Angkutan Laut/Ocean transportation services & Angkutan Laut/Marine \\
\hline 160 & $\begin{array}{l}\text { Jasa Angkutan Sungai Danau dan Penyeberangan/ } \\
\text { River, Lake and Crossing Transportation Services }\end{array}$ & Transportation \\
\hline 152 & $\begin{array}{l}\text { Jalan, Jembatan, dan Pelabuhan/Roads, Bridges and } \\
\text { Ports }\end{array}$ & $\begin{array}{l}\text { Bangunan Kelautan/Ocean } \\
\text { Infrastructures }\end{array}$ \\
\hline 156 & Jasa perdagangan/Trading Services & Jasa Kelautan/Ocean Services \\
\hline 162 & $\begin{array}{l}\text { Jasa Penunjang Angkutan/Transportation support } \\
\text { services }\end{array}$ & \\
\hline 176 & $\begin{array}{l}\text { Jasa Persewaan dan Jasa Penunjang Usaha/Rental } \\
\text { Services and Business Support Services }\end{array}$ & \\
\hline
\end{tabular}

Sumber: Hasil Analisis Data (2019)/Source : Data Analysis Result (2019) 
Tabel 2. Kontribusi PDB Kelautan terhadap PDB Nasional. Table 2. Contribution of Marine GDP to National GDP.

\begin{tabular}{cllrc}
\hline No & \multicolumn{1}{c}{ Sektor/Sector } & $\mathbf{2 0 0 5}$ & $\mathbf{2 0 1 0}$ & $\mathbf{2 0 1 5}$ \\
\hline 1 & Perikanan/Fisheries & $1.87 \%$ & $2.13 \%$ & $2.23 \%$ \\
2 & Pariwisata Bahari/Marine tourism & $4.95 \%$ & $3.42 \%$ & $2.83 \%$ \\
3 & Pertambangan Laut/Ocean Mining & $2.67 \%$ & $3.56 \%$ & $3.91 \%$ \\
4 & Industri Kelautan/Marine Industry & $3.42 \%$ & $3.81 \%$ & $3.96 \%$ \\
5 & Angkutan Laut/Marine Transportation & $0.98 \%$ & $0.35 \%$ & $0.10 \%$ \\
6 & Bangunan Kelautan/Ocean Infrastructures & $3.86 \%$ & $2.60 \%$ & $2.11 \%$ \\
7 & Jasa Kelauta /Ocean Services & $7.64 \%$ & $11.42 \%$ & $12.88 \%$ \\
Persentase GDP Kelautan/Percentage of Ocean GDP & $25.39 \%$ & $27.28 \%$ & $28.01 \%$ \\
\hline
\end{tabular}

Sumber: Hasil Analisis Data (2019)/Source : Data Analysis Result (2019)

Berdasarkan tabel tersebut, dapat dilihat bahwa sektor jasa kelautan memiliki share yang paling besar dengan trend yang terus meningkat. Sektor perikanan, pertambangan, industri kelautan juga mengalami peningkatan. Akan tetapi beberapa sektor: pariwisata bahari, angkutan laut, dan bangunan kelautan mengalami penurunan. Jasa kelautan yang terdiri dari jasa perdagangan menyumbang GDP kelautan sebesar 12,88 \% disusul oleh industri kelautan, pertambangan dan pariwisata bahari.

Pada Tabel 3 disajikan struktur permintaan dan penawaran bidang kelautan tahun 2015. Total output bidang kelautan adalah sebesar Rp3,590 triliun. Nilai ini menyumbang $27,39 \%$ dari total output nasional. Nilai GDP bidang kelautan adalah sebesar Rp2,026 triliun. Sektor jasa kelautan menyumbang output dan GDP yang paling besar yaitu $35,37 \%$ dan $41,86 \%$. Sektor yang paling kecil adalah angkutan laut yakni 2,20\% dari total output kelautan dan 1,26 \% dari GDP kelautan.

Pada sisi permintaan, permintaan akhir domestik adalah yang paling besar nilainya $(45,95 \%)$. Disusul permintaan antara sebesar adalah $41,39 \%$ dan ekspor sebanyak $12,66 \%$. Dari sisi penawaran, nilai impor hanya sebanyak $7,39 \%$ dan output domestik sebesar 92,61\%. Dilihat dari perbandingan ekspor dan impor maka terdapat net ekspor sebesar $5,27 \%$. Struktur permintaan dan penawaran bidang kelautan dan sektor selain kelautan disajikan pada Tabel 3.

Sektor bangunan kelautan dan angkutan laut masih banyak mengandalkan komponen impor. Hal ini disebabkan industri hulu pada kedua sektor ini belum berkembang di dalam negeri.

Tabel 3. Struktur Permintaan dan Penawaran Bidang Kelautan (Rp Juta) Tahun 2015. Table 3. Demand and Supply Structure of the Ocean Sector (Million IDR) in 2015.

\begin{tabular}{|c|c|c|c|c|c|c|c|c|}
\hline \multirow[b]{2}{*}{ No } & \multirow[b]{2}{*}{ Sektor/Sector } & \multirow{2}{*}{$\begin{array}{l}\text { Permintaan } \\
\text { Antara/ } \\
\text { Intermediate } \\
\text { Demand }\end{array}$} & \multicolumn{2}{|c|}{ Permintaan Akhir/ Final Demad } & \multirow[b]{2}{*}{$\begin{array}{l}\text { Permintaan/ } \\
\text { Demand }\end{array}$} & \multirow[b]{2}{*}{ Impor/ Import } & \multirow{2}{*}{$\begin{array}{c}\text { Output } \\
\text { Domestik/ } \\
\text { Domestic } \\
\text { Output }\end{array}$} & \multirow[b]{2}{*}{$\begin{array}{l}\text { Penawaran/ } \\
\text { Supply }\end{array}$} \\
\hline & & & $\begin{array}{l}\text { Domestik/ } \\
\text { Domestic }\end{array}$ & $\begin{array}{l}\text { Ekspor/ } \\
\text { Export }\end{array}$ & & & & \\
\hline \multirow[t]{2}{*}{1} & Perikanan/Fisheries & $71,782,759$ & $149,847,717$ & $23,827,988$ & $245,458,464$ & $3,237,951$ & $242,220,513$ & $245,458,464$ \\
\hline & Persentase/Percentage & $29.24 \%$ & $61.05 \%$ & $9.71 \%$ & $100.00 \%$ & $1.32 \%$ & $98.68 \%$ & $100.00 \%$ \\
\hline \multirow[t]{2}{*}{2} & Pariwisata Bahari/Marine Tourism & $128,380,638$ & $376,528,977$ & $45,990,961$ & $550,900,576$ & $12,512,355$ & $538,388,221$ & $550,900,576$ \\
\hline & Persentase/Percentage & $23.30 \%$ & $68.35 \%$ & $8.35 \%$ & $100.00 \%$ & $2.27 \%$ & $97.73 \%$ & $100.00 \%$ \\
\hline \multirow[t]{2}{*}{3} & Pertambangan Laut/Ocean Mining & $258,792,315$ & $3,302,340$ & $102,354,192$ & $364,448,847$ & $16,890,488$ & $347,558,359$ & $364,448,847$ \\
\hline & Persentase/ Percentage & $71.01 \%$ & $0.91 \%$ & $28.08 \%$ & $100.0 \%$ & $4.63 \%$ & $95.37 \%$ & $100.00 \%$ \\
\hline \multirow[t]{2}{*}{4} & Industri Kelautan/Marine Industry & $233,692,989$ & $79,292,669$ & $131,744,038$ & $444,729,696$ & $58,824,733$ & $385,904,963$ & $444,729,696$ \\
\hline & Persentase/ Percentage & $52.55 \%$ & $17.83 \%$ & $29.62 \%$ & $100.00 \%$ & $13.23 \%$ & $86.77 \%$ & $100.00 \%$ \\
\hline \multirow[t]{2}{*}{5} & Transportasi Laut/ Marine Transportation & $244,861,233$ & $48,496,013$ & $12,552,974$ & $305,910,220$ & $15,271,085$ & $290,639,135$ & $30,5910,220$ \\
\hline & Persentase/ Percentage & $80.04 \%$ & $15.85 \%$ & $4.10 \%$ & $100.00 \%$ & $4.99 \%$ & $95.01 \%$ & $100.00 \%$ \\
\hline \multirow[t]{2}{*}{6} & $\begin{array}{l}\text { Bangunan Kelautan/Ocean } \\
\text { Infrastructures }\end{array}$ & $13,340,440$ & $525,753,330$ & 0 & $539,093,770$ & $56,028,325$ & $483,065,445$ & $539,093,770$ \\
\hline & Persentase/Percentage & $2.47 \%$ & $97.53 \%$ & $0.00 \%$ & $100.00 \%$ & $10.39 \%$ & $89.61 \%$ & $100.00 \%$ \\
\hline \multirow[t]{2}{*}{7} & Jasa Kelautan/Ocean Services & $589,657,493$ & $492,393,245$ & $187,572,561$ & $1,269,623,299$ & $32,679,190$ & $1,236,944,109$ & $1,269,623,299$ \\
\hline & Persentase/Percentage & $46.44 \%$ & $38.78 \%$ & $14.77 \%$ & $100.00 \%$ & $2.57 \%$ & $97.43 \%$ & $100.00 \%$ \\
\hline \multirow[t]{2}{*}{8} & Sektor Lainnya/Other Sectors & $3,885,427,321$ & $434,8546,498$ & $11,5497,8691$ & $9,388,952,510$ & $772,862,871$ & $8,616,089,639$ & $9,388,952,510$ \\
\hline & Persentase/Percentage & $41.38 \%$ & $46.32 \%$ & $12.30 \%$ & $100.00 \%$ & $8.23 \%$ & $91.77 \%$ & $100.00 \%$ \\
\hline \multicolumn{2}{|c|}{ Jumlah/Total } & $5,425,935,188$ & $6,024,160,789$ & $1,659,021,405$ & $13,109,117,382$ & $968,306,998$ & $12,140,810,384$ & $13,109,117,382$ \\
\hline \multicolumn{2}{|c|}{ Persentase/Percentage } & $41.39 \%$ & $45.95 \%$ & $12.66 \%$ & $100.00 \%$ & $7.39 \%$ & $92.61 \%$ & $100.00 \%$ \\
\hline \multicolumn{2}{|r|}{ Total Sektor Kelautan/Ocean Sector Total } & $1,540,507,867$ & $1,675,614,291$ & $504,042,714$ & $3,720,164,872$ & $195,444,127$ & $3,524,720,745$ & $3,720,164,872$ \\
\hline \multicolumn{2}{|r|}{ Persentase/Percentage } & $11.75 \%$ & $12.78 \%$ & $3.84 \%$ & $28.38 \%$ & $1.49 \%$ & $26.89 \%$ & $28.38 \%$ \\
\hline
\end{tabular}

Sumber: Hasil Analisis Data (2019)/Source : Data Analysis Result (2019) 


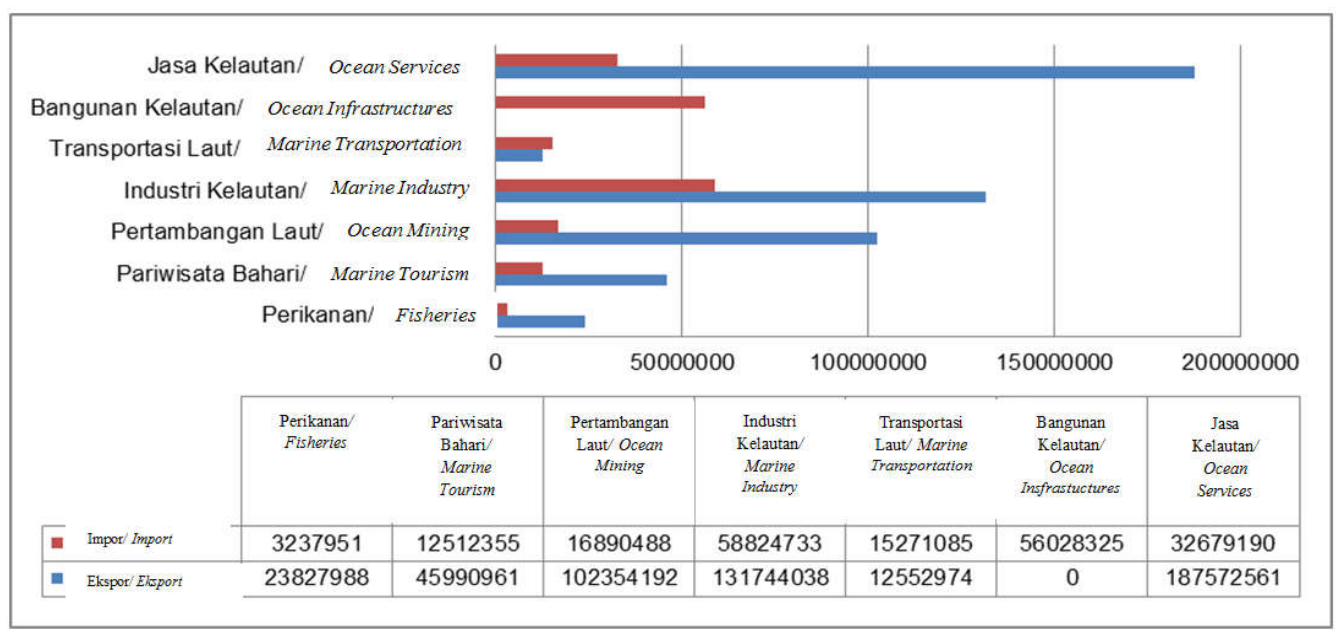

Gambar 2. Perbandingan Ekspor dan Impor Bidang Kelautan (Rp Juta) Tahun 2015.

Figure 2. Comparation of Export and Import in Marine Sector (Million IDR) in 2015.

Jika dilihat pada sektor berbasis sumberdaya seperti perikanan, pertambangan, industri maritim dan pariwisata bahari, nilai ekspor jauh lebih besar dibandingkan impor. Demikian pula dengan jasa kelautan. Pada Gambar 2 terlihat bahwa sektor bangunan kelautan dan angkutan laut masih banyak mengandalkan komponen impor yang masing masing sebesar $10,39 \%$ dan $4,99 \%$. Hal ini disebabkan industri hulu pada kedua sektor ini belum berkembang di dalam negeri. Jika dilihat pada sektor berbasis sumber daya seperti perikanan, pertambangan, industri maritim dan pariwisata bahari, nilai ekspor jauh lebih besar dibandingkan impor. Nilai ekspor perikanan sebesar Rp23 triliun, pariwisata bahari Rp45 triliun, pertambanagan laut Rp102 triliun, industri kelautan Rp132 triliun dan jasa kelautan sebesar Rp187 triliun.
Dilihat dari segi outputnya yang merupakan nilai produk yang dihasilkan, ekonomi kelautan didominasi oleh sektor jasa kelautan yang menjadi pondasi perekonomiannya pada ekonomi bidang kelautan yaitu $9,69 \%$. Struktur nilai tambah yang merupakan upah dan gaji serta keuntungan usaha, juga menunjukkan jasa kelautan ini mampu memberikan kontribusi yang signifikan sebesar $13,36 \%$. Persentase nilai output dan nilai tambah sektor kelautan disajikan pada Tabel 4

Tabel 5 menunjukkan komposisi permintaan akhir bidang kelautan. Dari sisi permintaan akhir bidang kelautan, konsumsi rumah tangga menyumbang sebesar Rp2,360 triliun atau sebesar $43.53 \%$. Posisi kedua adalah investasi $(25,38 \%)$ dan disusul investasi sebesar $25,38 \%$. Konsumsi pemerintah memiliki nilai terkecil sebesar 11,29\%. Tabel 5 menyajikan komposisi permintaan akhir bidang kelautan.

Tabel 4. Persentese Nilai Output dan Nilai Tambah Sektor Kelautan.

Table 4. Percentage of Output Value and Added Value of Marine Sector.

\begin{tabular}{llcc}
\hline No & \multicolumn{1}{c}{ Sektor/Sector } & $\begin{array}{c}\text { Persentase Output / } \\
\text { Output Percentage (\%) }\end{array}$ & $\begin{array}{c}\text { Persentase Nilai Tambah / } \\
\text { Added Value Percentage (\%) }\end{array}$ \\
\hline 001 & Perikanan/Fisheries & 1.87 & 2.83 \\
002 & Pariwisata Bahari/Marine tourism & 4.20 & 3.37 \\
003 & Pertambangan Laut/Ocean Mining & 2.78 & 4.80 \\
004 & Industri Kelautan/Marine Industry & 3.39 & 4.55 \\
005 & Angkutan Laut/Marine Transportation & 2.33 & 0.37 \\
006 & Bangunan Kelautan/Ocean & 4.11 & 2.49 \\
& Infrastructures & & 13.36 \\
\hline
\end{tabular}

Sumber: Hasil Analisis Data (2019)/Source: Data Analysis Result (2019) 
Tabel 5. Komposisi Permintaan Akhir Bidang Kelautan.

Table 5. Composition of Final Demand of the Ocean Sector.

\begin{tabular}{lcc}
\hline \multicolumn{1}{c}{ Permintaan Akhir/Final Demand } & $\begin{array}{c}\text { Nilai (Rp Juta)/ } \\
\text { Value (Rp Million) }\end{array}$ & $\begin{array}{c}\text { Persentasel } \\
\text { Percentage }\end{array}$ \\
\hline Konsumsi RT/Household Consumption & $2,360,198,165$ & $43.53 \%$ \\
Konsumsi Pemerintah/Government Consumption & $611,969,097$ & $11.29 \%$ \\
Investasi/Investation & $1,376,379,236$ & $25.38 \%$ \\
Ekspor/Export & $1,074,007,701$ & $19.81 \%$ \\
\hline
\end{tabular}

Sumber: Hasil Analisis Data (2019)/Source: Data Analysis Result (2019)

Struktur permintaan akhir ini menunjukkan konsumsi rumah tangga masih dominan dalam penentuan nilai output nasional yaitu sebesar $43,53 \%$. Komponen investasi juga menjadi penunjang dalam struktur permintaan akhir bidang kelautan. Ini berarti peningkatan investasi akan mampu mendorong nilai output secara signifikan.

\section{DAMPAK PENGEMBANGAN EKONOMI KELAUTAN}

Urgensi sektor dalam perekonomian dapat dilihat juga dari dampak terhadap output, kesempatan kerja dan pendapatan. Pada Tabel 6 didapatkan hasil analisis dampak pada pengganda output menunjukkan industri kelautan adalah sektor primer karena paling besar nilainya yaitu 1.5567. Hasil ini menunjukkan bahwa adanya peningkatan permintaan akhir sebesar satu unit uang secara rata-rata akan mendorong peningkatan produksi yang menghasilkan pembentukan output baru dalam perekonomian suatu daerah sebesar
1.5567 unit. Analisis pengganda kesempatan kerja juga menghasilkan kesimpulan bahwa industri kelautan yang paling besar yaitu 0,1180. Ini berarti sektor industri kelautan merupakan sektor paling berpotensi untuk mendorong peningkatan kesempatan kerja. Begitu juga analisis pengganda pendapatan yang menunjukkan industri maritim memiliki nilai 0,2006 sehingga industri ini mampu mendorong peningkatan pendapatan.

Penentuan fokus pembangunan diharapkan pada sektor-sektor yang mampu memberikan multiplier effect yang besar pada pengembangan ekonomi lainnya. Berdasarkan hasil analisis keterkaitan kedepan dan keterkaitan kebelakang bidang kelautan yang disajikan pada Tabel 7 , terlihat bahwa hanya beberapa sektor yang memiliki nilai koefisien lebih dari 1. Ini berarti dapat dikatakan bahwa sektor-sektor tersebut mampu berperan sebagai sektor kunci dalam perekonomian nasional.

Tabel 6. Hasil Analisis Dampak Pembangunan Ekonomi Kelautan terhadap Pengganda Output, Pengganda Kesempatan Kerja, dan Pengganda Pendapatan di Berbagai Sektor.

Table 6. Impact Analysis Result of Ocean Economic Development on Output Multiplier, Job Opportunity Multiplier and Income Multiplier.

\begin{tabular}{llccc}
\hline No. & Sektor/Sector & $\begin{array}{c}\text { Pengganda Output// } \\
\text { Output Multiplier }\end{array}$ & $\begin{array}{c}\text { Pengganda Kesempatan Kerja/ } \\
\text { Job Opportunity Multiplier }\end{array}$ & $\begin{array}{c}\text { Pengganda Pendapatan/ } \\
\text { Income Multiplier }\end{array}$ \\
\hline 1 & $\begin{array}{l}\text { Perikanan/Fisheries } \\
\text { Pariwisata Bahari/ }\end{array}$ & 1.1769 & 0.0602 & 0.1024 \\
2 & 1.4626 & 0.1030 & 0.1751 \\
3 & $\begin{array}{l}\text { Marine tourism } \\
\text { Pertambangan Laut/ } \\
\text { Ocean Mining } \\
\text { Industri Kelautan/ } \\
\text { Marine Industry } \\
\text { Angkutan }\end{array}$ & 1.2409 & 0.0752 & 0.1278 \\
$\begin{array}{l}\text { Laut/Marine } \\
\text { Transportation }\end{array}$ & 1.5567 & 0.1180 & 0.2006 \\
6 & 1.1077 & 0.0179 & 0.0304 \\
$\begin{array}{l}\text { Bangunan } \\
\text { Kelautan/Ocean } \\
\text { Infrastructures } \\
\text { Jasa Kelautan/ } \\
\text { Ocean Services }\end{array}$ & 1.4405 & 0.0826 & 0.1404 \\
\hline
\end{tabular}

Sumber: Hasil Analisis Data (2019)/Source: Data Analysis Result (2019) 
Tabel 7. Hasil Analisis Dampak Keterkaitan Kedepan dan Keterkaitan Kebelakang bidang Kelautan terhadap Daya Penyebaran dan Derajat Kepekaan.

Table 7. Impact Analysis Result of Forward Linkage and Backward Linkage in Ocean Sectors to Power Spread and Degree of Sensitivity.

\begin{tabular}{llcc}
\hline No. & \multicolumn{1}{c}{ Sektor/Sector } & $\begin{array}{c}\text { Penyebaran/ } \\
\text { Spread Power }\end{array}$ & $\begin{array}{c}\text { Derajat Kepekaan/ } \\
\text { Degree of Sensitivity }\end{array}$ \\
\hline 1 & Perikanan/Fisheries & 0.8793 & 0.8344 \\
2 & Pariwisata Bahari/Marine tourism & 1.0928 & 0.8035 \\
3 & Pertambangan Laut/Ocean Mining & 0.9272 & 0.9738 \\
4 & Industri Kelautan/Marine Industry & 1.1631 & 0.8775 \\
5 & Angkutan Laut/Marine Transportation & 0.8276 & 0.7943 \\
6 & Bangunan Kelautan/Ocean & 1.0763 & 0.7520 \\
& Infrastructures & & \\
7 & Jasa Kelautan/Ocean Services & 0.9634 & 0.9567 \\
8 & Sektor Lainnya/Other Sectors & 1.0702 & 2.0079 \\
\hline
\end{tabular}

Sumber: Hasil Analisis Data (2019)/Source: Data Analysis Result (2019)

Berdasarkan angka pengganda tenaga kerja, sektor industri kelautan dan pariwisata bahari memiliki nilai pengganda yang paling besar yaitu 1.181 dan 1.1031. Ini berarti sektor ini merupakan penyerap tenaga kerja yang tinggi sehingga sektor ini merupakan sektor yang padat karya. Sektor angkutan laut dan pertambangan adalah sektor yang memiliki pengganda tenaga kerja yang kecil yaitu 0,179 dan 0,752. Ini menunjukkan sektor ini adalah sektor yang padat modal.

Daya penyebaran dapat disebut juga sebagai hubungan keterkaitan ke belakang (backward lingkage). Pada dasarnya derajat kepekaan merupakan hubungan yang terjadi dengan bahan mentah ataupun bahan bakunya. Sektor yang mempunyai daya penyebaran yang tinggi memberikan indikasi bahwa, sektor tersebut mempunyai keterkaitan ke belakang atau memiliki ketergantungan yang tinggi terhadap sektor yang lainnya. Adapun indeks daya penyebaran yang kuat memberikan indikasi bahwa sektor-sektor yang mempunyai indeks derajat kepekaan lebih besar dari 1, berarti daya penyebaran sektor tersebut di atas rata-rata derajat kepekaan secara keseluruhan. Dari Tabel 7 terlihat bahwa 3 sektor dengan nilai koefisien lebih dari 1 yaitu industri kelautan $(1,1631)$, pariwisata bahari $(1,0928)$, dan bangunan kelautan $(1,0763)$. Pada industri kelautan menunjukkan bahwa setiap kenaikan 1 unit output industri kelautan, maka akan menyebabkan naiknya output sektor-sektor lainnya (termasuk sektor industri kelautan sendiri) secara keseluruhan sebesar 1,1631 unit.

Derajat kepekaan merupakan hubungan yang terjadi antara input dengan barang jadinya. Sektor yang mempunyai daya penyebaran tinggi memberikan indikasi bahwa, sektor tersebut mempunyai keterkaitan ke depan (forward lingkage) atau memiliki daya dorong yang cukup kuat dibandingkan terhadap sektor yang lainnya. Adapun indeks derajat kepekaan memberikan indikasi bahwa, sektor-sektor yang mempunyai indeks daya penyebaran lebih besar dari 1, berarti daya penyebaran sektor tersebut di atas rata-rata derajat kepekaan secara keseluruhan. Sektor yang memiliki derajaan kepekaan yang tinggi hanya sektor lainnya yaitu sebesar 2.0079. Ini berarti bahwa setiap kenaikan 1 unit output sektor lainnya, maka akan menyebabkan naiknya kebutuhan input dari sektor-sektor lainnya secara keseluruhan sebesar 2.0079 unit.

Analisis koefisien penyebaran dan derajat kepekaan pada bidang kelautan menunjukkan sebagian besar sektor kelautan berorientasi pada pasar input domestik. Ini terlihat dari nilai koefisien penyebarannya yang lebih besar dari pada derajat kepekaan. Sektor ini adalah perikanan, pariwisata bahari, industri kelautan, angkutan laut, bangunan kelautan dan jasa kelautan. Sedangkan sektor pertambangan laut menunjukkan nilai koefisien penyebarannya yang lebih kecil dari pada derajat kepekaan sehingga sektor ini lebih banyak menggunakan input produksi dari luar wilayah.

\section{SINTESA KEBIJAKAN}

Merujuk pada hasil kajian ini, terlihat bahwa masing-masing sektor ekonomi mempunyai peran masing-masing dalam mendorong perekonomian. Sektor pariwisata bahari, industri kelautan, bangunan kelautan memiliki daya penyebaran diatas rata-rata. Sektor perikanan, pariwisata bahari, industri kelautan, angkutan laut, 
bangunan kelautan, jasa kelautan berorientasi pada pasar input domestik. Berdasarkan indikatorindikator tersebut, prioritas pengembangan ekonomi yang memiliki pengungkit terbesar adalah industri kelautan, perikanan dan pariwisata bahari. Pengembangan kedua sektor tersebut bukan berarti melupakan sektor-sektor lainnya karena ada keterkaitan dalam sistem ekonomi yang tak terpisahkan diantara komponen ekonomi bidang kelautan.

Pada aspek pengembangan aktivitas secara lebih detail, sektor perikanan yang berdampak besar pada penyerapan tenaga kerja dan pengembalian modal adalah pengolahan dan pengawetan ikan. Sektor pariwisata bahari yang perlu difokuskan pengembangannya adalah penyediaan akomodasi, penyediaan makan dan minum, dan jasa menunjang pariwisata seperti kesenian dan rekreasi alam. Pada industri kelautan yang perlu dikembangkan adalah pengolahan minyak lepas pantai. Sektor angkutan laut yang mampu menyerap tenaga lokal adalah jasa angkutan laut dan jasa penyeberangan sungai. Sebagai penunjang dalam konektivitas, maka sektor bangunan kelautan berupa pelabuhan harus dilengkapi dengan jasa kepelabuhan yang memadai (Sapanli et al., 2018).

Pengembangan aktivitas pada sektor-sektor tersebut harus mampu mengikuti perkembangan teknologi pada masa revolusi industri 4.0 saat ini. Salah satu sektor yang paling erat adalah sektor pariwisata bahari. Perubahan gaya hidup saat ini menuntut adanya kecepatan dan kemudahan dalam mendapatkan informasi. Ini merupakan tantangan dalam pengembangan bisnis pariwisata bahari dalam menggandeng start-up bisnis dan sosial media dalam meningkatkan pengembangan industri ini. Sektor lain yang menuntuk adaptasi perkembangan teknologi adalah angkutan laut yang lebih efesien dan mudah diakses ketersediaannya.

Melihat dampak yang signifikan pada masing-masing sektor, pengembangan aktivitas ekonomi kelautan perlu didukung kebijakan yang tepat. Selain mengandalkan pertumbuhan ekonomi, bidang kelautan harus memperhatikan faktor pembatas berupa daya dukung ekosistem yang berkelanjutan (Sapanli, 2009). Prinsip kebijakan pengembangan ekonomi kelautan harus inovatif dan berkelanjutan yang bertumpu pada peningkatan daya saing, modernisasi sistem produksi, penguatan kapasitas pelaku industri dan berbasis komoditas (Fritz \& Hanus 2015).
Meningkatkan nilai tambah dan daya saing melalui peningkatan nilai tambah dan daya saing produk untuk ekspor dan memenuhi kebutuhan dalam negeri. Modernisasi sistem produksi dengan cara efisiensi dan modernisasi sistem produksi hulu dan hilir. Penguatan pelaku industri kelautan dengan cara peningkatan jumlah, kapasitas, dan kualitas industri kelautan dan perikanan dan pembinaan hubungan antar entitas bisnis dan industri pada semua tahapan value chain untuk memperkuat struktur industri kelautan (Wiyono \& Mustaruddin 2013). Berbasis komoditas, wilayah, dan sistem manajemen kawasan melalui konsentrasi pada komoditas unggulan, potensi wilayah dan manajemen sentra-sentra produksi potensial sesuai dengan prospek pertumbuhannya di masa depan. Dalam rangka pencapaian tersebut perlu dilakukan transformasi sosial melalui peningkatan kapasitas SDM kelautan perikanan dengan perubahan cara berfikir dan perilaku masyarakat modern. Pembangunan bidang kelautan yang berkelanjutan dengan prinsip keseimbangan antara pemanfaatan sumberdaya alam dan perlindungan lingkungan berjangka panjang (Sadelie, 2012).

Konsep pembangunan yang berbasis spasial yang berkelanjutan di bidang kelautan kita kenal dengan istilah blue economy. Menurut Kusumastanto (2012) model wilayah berbasis blue economy mengharuskan adanya integrasi antar sektor. Pertama : multi bisnis terintegrasi: pengembangan investasi dengan kenekaragaman kegiatan ekonomi yang saling terkait: efisiensi sumberdaya alam tapi perkaya hasil produksi dan nilai serta memperluas kesempatan kerja. Kedua adalah kawasan gugusan pulau-pulau kecil model pengelolaan ekonomi wilayah kepulauan: kawasan yang terdiri dari pulau-pulau kecil terpisah dari pulau besar atau pulau-pulau kecil yang menjadi bagian ekosistem pulau besar. Ketiga, kawasan teluk yaitu model pengelolaan teluk dan daratan terintegrasi: kawasan teluk relatif luas yang telah dan diproyeksikan menjadi kawasan ekonomi dengan keanekaragaman kegiatan tinggi. Keempat, kawasan konservasi yaitu model pengembangan ekonomi kawasan terbatas: kawasan ekonomi khusus berbasis konservasi (Sullivan et al., 2014).

Mengingat perkembangan ekonomi kelautan yang memiliki kecenderungan positif, maka pemerintah perlu memperhatikan aspek regulasi dan dukungan secara nyata dalam hal pengembangan infrastruktur (Torres et al., 2015). Diharapkan dengan model ini mampu menjadi alat perencanaan dalam merumusan kebijakan 
pembangunan kelautan. Semua pihak, khususnya pemangku kebijakan dalam sektor-sektor terkait hendaknya perlu mendorong pertumbuhan ekonomi kelautan ini dengan keberpihakan dan perencanaan kebijakan yang nyata dari aspek penganggaran, regulasi dan iklim investasi (Kusumastanto, 2015).

Pembangunan ekonomi kelautan menjadi harapan bangsa untuk mampu bersaing pada konsteks global. Dengan potensi ekonomi kelautan yang merupakan keunggulan komparatif, harus mampu ditransformasikan kedalam keunggulan kompetitif guna menumbuhkan daya saing bangsa. Pembangunan yang selaras dengan lingkungan yang berbasis inovasi akan mampu menjadikan pembangunan kelautan ini menjadi lebih maju dan mampu menjadi prime mover ekonomi bangsa. Untuk mencapai itu semua perlu adanya konsensus bersama antar sektor ekonomi kelautan untuk bersinergi dan saling mendukung satu sama lainnya.

\section{IMPLIKASI KEBIJAKAN}

Berdasarkan hasil tersebut dapat kita simpulkan bahwa sektor yang memiliki dampak besar pada pertambahan output dan penyerapan tenaga kerja yang tinggi adalah industri kelautan, perikanan dan pariwisata bahari. Implikasi kebijakan yang harus dilakukan adalah meningkatkan produktivitas pada kedua sektor ini sehingga mampu meningkatkan nilai koefisien teknis serta menambah investasi yang pada akhirnya mampu berpengaruh pada efesiensi Incremental Capital Output Ratio (ICOR) dan Incremental Labour Output Ratio (ILOR).

Industri kelautan merupakan sektor usaha yang sangat potensial dan strategis untuk terus dikembangkan. Pengembangan industri kelautan harus fokus pada kualitas sumberdaya manusia (SDM) serta penerapan teknologi dan inovasi. Tantangan revolusi industri 4.0 menuntut perkembangan teknologi yang disertai SDM yang mampu mengoperasikannya. Jika tidak maka inovasi pada industri kelautan justru akan menciptakan pengangguran karena tenaga manusia akan tergantikan oleh mesin dan robot. Berdasarkan hasil tersebut, pemerintah perlu melakukan dan mendorong upaya pengembangan industri kelautan Indonesia ke depan yang ditujukan bagi peningkatan investasi secara signifikan, seperti dengan memberikan berbagai iklim investasi yang kondusif berupa kemudahan-kemudahan serta program dan kegiatan bagi peningkatan kapasitas para pelaku usaha dan kinerja organisasi (perusahaan) yang terkait.

Pemanfaatan perikanan jika sudah pada kondisi optimal diperlukan penambahan jumlah kapal untuk meningkatkan eksploitasi sehingga pertumbuhan ikan menjadi optimal dan tingkat kematian alami menjadi lebih rendah. Penambahan kapal dapat dilakukan oleh pemerintah daerah, pemerintah pusat dan pihak swasta dengan spesifikasi jenis alat tangkap, ukuran dan teknologi kapal perikanan ramah lingkungan yang sesuai untuk melakukan penangkapan ikan di ZEE. Dalam memperlancar aktivitas penangkapan ikan diperlukan tambahan infrastruktur penangkapan seperti pelabuhan, dermaga, fasilitas pendaratan ikan, fasilitas penyimpanan, fasilitas pengolahan dan pemasaran perikanan, sehingga sumberdaya perikanan memberikan manfaat optimal.

Dalam rangka pengembangan ekonomi yang berkelanjutan, perikanan tangkap yang ekstraktif perlu diselaraskan dengan rencana KEK dalam pengembangan melalui penyiapan kawasan yang memiliki keunggulan geoekonomi dan geostrategi dan berfungsi untuk menampung kegiatan industri, ekspor, impor, dan kegiatan ekonomi lain yang memiliki nilai ekonomi tinggi dan daya saing internasional. Kehadiran KEK pada setiap WPP diharapkan membangun kemampuan dan daya saing ekonomi pada level nasional melalui industri perikanan dan pariwisata bernilai tambah dan berantai nilai. Pengembangan pariwisata bahari diwujudkan dengan penambahan kawasan wisata baru. Selama ini destinasi wisata bahari masih tergantung pada Pulau Bali, padahal masih banyak potensi wisata di wilayah lain, khususnya wilayah timur yang memiliki keindahan alam dan daya tarik wisata yang memukau. Pemerintah tengah mengembangkan beberapa kawasan wisata bahari sebagai alternative Bali yaitu Tanjung Kelayang, Tanjung Lesung, Kepulauan Seribu, Mandalika, Labuan Bajo, Wakatobi, dan Murotai.

Guna mencapai hal tersebut, diperlukan strategi pengembangan wisata yang terencana. Pengembangan destinasi baru tersebut dapat dilakukan dengan meningkatkan 3A yaitu Atraksi dengan menambah aktivitas wisata, Aksesibilitas yaitu mempermudah jalur transportasi , Amenitas yaitu peningkatan kualitas dan kuantitas akomodasi serta kebersihan dan kenyamanan di lingkungan destinasi. Selain itu penting juga mempersiapkan pelaku usaha pariwisata baik SDM pelaksana, masyarakat, dan industri. Peningkatan SDM 
pariwisata dilakukan dengan pelatihan peningkatan kapasitas seperti penguasaan bahasa asing dan sertifikasi profesi bidang pariwisata. Penyiapan masyarakat yang mendukung iklim wisata dapat dilakukan dengan pelatihan kompetensi kerajinan lokal dan pendampingan kelompok sadar wisata. Industri pariwisata juga perlu disiapkan dengan sertifikasi usaha perhotelan dan rumah makan seperti kewajiban melakukan sertifikasi halal.

Mengingat diperoleh perkembangan ekonomi kelautan yang memiliki trend positif, maka pemerintah perlu memperhatikan aspek regulasi (PP atau Permen) berupa peraturan dan perundangan turunan UU Kelautan dan dukungan secara nyata dalam hal pengembangan infrastruktur. Pemerintah juga perlu memperhatikan sektorsektor yang menjadi kunci pada pembangunan ekonomi kelautan. Sektor industri kelautan perlu didukung dengan memperkuat infrastruktur yang didukung kelembagaan yang kuat karena mampu memberikan multipier effect yang besar dalam percepatan membangunan. Pada sektor pariwisata bahari perlu ditingkatkan promosi dan kemudahan aksesibilatas transportasi serta akomodasi yang terjamin kualitasnya.

\section{UCAPAN TERIMA KASIH}

Ucapan terima kasih disampaikan kepada pihak Badan Pusat Statistik yang telah menyediakan data dasar dan Bapak Dedy Miharja Deputi 1 Kementerian Koordinator Kemaratiman atas bantuan dalam pelaksanaan diskusi yang membantu melengkapi data ekonomi kelautan.

\section{PERNYATAAN KONTRIBUTOR}

Kontributor dalam karya tulis ilmiah ini adalah Kastana Sapanli sebagai kontributor utama, dan Tridoyo Kusumastanto, Sugeng Budiharsono, dan Agus Sadelie sebagai kontributor anggota yang sudah disepakati bersama-sama untuk diketahui semua pihak yang berkepentingan.

\section{DAFTAR PUSTAKA}

Babaa, H., Watanabe, T., Nagaishi, M. \& Matsumoto H. (2014). Area Business Continuity Management, A New Opportunity for Building Economic Resilience. Procedia Economics and Finance. 18: 296 - 303

Bainbridge JM,. Potts T. \& O'Higgins TG. (2011). Rapid Policy Network Mapping: A New Method for Understanding Governance Structures for Implementation of Marine Environmental Policy. Journal of PLoS ONE. 6(10): e26149. doi:10.1371/journal. pone.0026149.

[BPS] Badan Pusat Statistik. (2018). Laporan Perekonomian Indonesia 2018. Jakarta, ID: Central for Statistical Services.

(2015). Tabel Input-Output Indonesia 2010. Jakarta, ID: Central for Statistical Services.

[BPS] Badan Pusat Statistik. (2000). Kerangka Teori dan Analisis Tabel Input Output. Jakarta, ID: Central for Statistical Services.

Bui, T., Duong, M. H. \&Nguyen, VH. (2013). Vietnam Inter-Regional Input-Output Analysis: The Bi-Regional and 8-Regional Cases of Vietnam. Journal of Contemporary Management.

Bui, T., Kobayashi, K., Thai, NQ. \&Phong NV. 2012. Multi-interregional economic impact analysis based on multi-interregional input output model consisting of 7 regions of Vietnam, 2000. Journal of Finance and Investment Analysis, vol.1, no.2: 83-117.

Colgan, C. S. (2013). The ocean economy of the United States: Measurement, distribution, \& trends. Journal of Ocean \& Coastal Management. 71: 334-343.

Colgan, C, S. (2016). Measurement of the Ocean Economy From National Income Accounts to the Sustainable Blue Economy. Journal of Ocean and Coastal Economics.Vol. 2: Iss. 2, Article 12. DOI: https://doi.org/10.15351/23738456.1061.

Dahuri, R. (2003). Paradigma Baru Pembangunan Indonesia Berbasis Kelautan. Orasi IImiah Guru Besar tetap Bidang Pengelolaan Sumberdaya Pesisir dan lautan. Fakultas Perikanan dan IImu Kelautan. Institut Pertanian Bogor, Bogor.

Dankel, DJ., Aps, R., Padda, G., Rockmann, C., van der Sluijs, JP., Wilson, DC. \&Degnbo IP. (2012). Advice under uncertainty in the marine system. ICES Journal of Marine Science. 69: 3-7.

Fauzi, A. (2005). Kebijakan Perikanan dan Kelautan, Isu, Sintesis, dan Gagasan. Jakarta, ID: PT Gramedia Pustaka Utama.

Fritz, JS. \& Hanus J. 2015. The European Integrated Maritime Policy:The Next Five Years. Journal of Marine Policy. 53:1-4.

Jiang, XZ., Liu, TY. \&Su, CW. (2014). China's Marine Eonomy and Regional Development. Journal of Marine Policy. 50: 227-237.

Kildow, J. \& Colgan. (2005). California,s Ocean Economy. California, USA: National Ocean Economics Program.

[KKP] Kementerian Kelautan Perikanan. (2018). Analisis Data Pokok Kelautan dan Perikanan 
2017. Jakarta, ID: Kementerian Kelautan Perikanan.

Kusumastanto, T. (1998). Rencana aksi Pembangunan Berkelanjutan Sumberdaya Pesisir dan Kelautan Indonesia. Bogor, ID: PKSPL-IPB.

Kusumastanto, T. (2003). Ocean Policy dalam Membangun Negeri Bahari di Era Otonomi Daerah. Jakarta, ID: PT Gramedia Pustaka Utama.

Kusumastanto, T. (2006). Ekonomi Kelautan (Ocean Economics - Oceanomics). Bogor,ID: PKSPL-IPB.

Kusumastanto, T. (2012). Pengembangan Konsep Blue Economy dalam Kerangka Pembangunan Nasional Berkelanjutan. Makalah Seminar Nasional Blue Economy. Bogor,ID: PKSPL-IPB.

Kusumastanto, T. (2015). Pengembangan Ekonomi Wisata Bahari Dalam Percepatan Pembangunan Ekonomi Kelautan Nasional. Bogor,ID: PKSPL-IPB.

Leontief, W. (1970). The Dynamic Invers Contributions to Input-Output Analysis. Vol. Amesterdam: North Holland.

Markus, T., Schlacke, S., \&Maier N. (2011). Legal Implementation of Integrated Ocean Policies: The EU's Marine Strategy Framework Directive. The International Journal of Marine and Coastal Law. 26: 59-90.

Moffat, I. \& Hanley, N. (2001). Modelling sustainable development: systems dynamic and input-ouput approaches. Journal of Environmental Modelling \& Software. 16: 545-557.

OECD. (2016). The Ocean Economy in 2030. Paris: OECD Publishing. doi:10.1787/9789264251724-en.

Park, KS. \&Kildow, JT. (2014). Rebuilding the Classification System of the Ocean Economy. Journal of Ocean and Coastal Economics. Vol. 2014: Iss. 1, Article 4. DOI: https://doi.org/10.15351/23738456.1001.

Saharuddin, AH. (2001). National Ocean Policy - New Opportunities for Malaysian Ocean Development. Journal of Marine Policy: 25: 427-436.

Sadelie, A. (2012). Model Pengelolaan Sumberdaya Pesisir Berkelanjutan Berbasis REDD+. Disertasi. Sekolah Pascasarjana Institut Pertanian Bogor.

Sapanli, K. (2009). Analisis Kebijakan Pembangunan Ekonomi Kelautan di Provinsi Kepulauan Bangka Belitung. Tesis. Sekolah Pascasarjana Institut Pertanian Bogor.

Sapanli, K., Kusumastanto, T., Budiharsono, S. \& Sadelie A 2018. Analisis Struktur Ekonomi Kelautan
Indonesia. Jurnal Mina Sains. ISSN: 2407-9030 Volume 4 Nomor 2, Oktober 2018. DOI: http:// dx.doi.org/10.30997/jms.v4i2.

Sievanen, L., Leslie, HM., Wondolleck, JM., Yaffee, SL., McLeod, KL. \& Campbell, LM. (2011). Linking top-down and bottom-up processes through the new U.S.National Ocean Policy. Journal of Conservation Letters. 4: 298-303.

Sullivan, CM., Conway, FDL., Pomeroy, C., Arber, MH. \& Wright, DJ. (2014). Combining geographic information systems and ethnography to better understand and plan ocean space use. Journal of Applied Geography. XXX: 1-8.

Tejerin. (2013). Tendensi Konvergensi Ekonomi Wilayah dan Peran Kelautan dalam Perekonomian Indonesia. Disertasi. Sekolah Pascasarjana Institut Pertanian Bogor.

Torres, H., Karger, FM., Keys, D., Thornton, H., Luther, M. \& Alsharif, K. (2015). Whither the U.S.National Ocean Policy Implementation Plan. Journal of Marine Policy. 53: 198-212.

Undang-Undang Nomor 17 Tahun 2007 tentang Rencana Pembangunan Jangka Panjang 2005-2025.

Viederyte, R. (2014). Lithuanian Maritime Sector's Clustering Economic Impact Evaluation. Proceeding of Social and Behavioral Sciences. 156: $292-297$.

Wiyono, ES. \&Mustaruddin. (2013). Faktor-Faktor yang Mempengaruhi Kinerja Pembangunan Perikanan: Studi Kasus Pada Perikanan Tangkap di Indramayu. Journal of Marine Fisheries. Vol. 7 , No. 1. Hal: 109-115.

Zhao, R., Hynes, S. \& He, GS. (2014). Defining and Quantifying China's Ocean Economy. Jornal of Marine Policy. 43:164-173. 